\title{
Correction to: In vivo detection of beta-amyloid at the nasal cavity and other skull-base sites: a retrospective evaluation of ADNI1/GO
}

\author{
Anish Kapadia, 1 (D) Prarthana Desai ${ }^{3} \cdot$ Adam A. Dmytriw $^{1,2} \cdot$ Pejman Maralani $^{1,2} \cdot$ Chris Heyn $^{1,2} \cdot$ Sandra Black $^{4,5}$. \\ Sean Symons ${ }^{1,2} \cdot$ For the Alzheimer's Disease Neuroimaging Initiative
}

Published online: 26 May 2021

(c) The Japanese Society of Nuclear Medicine 2021

\section{Correction to: \\ Annals of Nuclear Medicine (2021) 35:728-734 \\ https://doi.org/10.1007/s12149-021-01614-7}

In the original publication of the article, the third author name should be "Adam A. Dmytriw" and not "Adam Dmytriw".

Publisher's Note Springer Nature remains neutral with regard to jurisdictional claims in published maps and institutional affiliations.

The original article can be found online at https://doi.org/10.1007/ s12149-021-01614-7.

Anish Kapadia

anish.kapadia@mail.utoronto.ca

1 Department of Medical Imaging, Sunnybrook Health Sciences Centre, Toronto M4N 3M5, Canada

2 Department of Medical Imaging, University of Toronto, 263 McCaul Street, 4th Floor, Toronto, ON M5T 1W7, Canada

3 Department of Medicine, Maharaja Sayajirao University of Baroda, Vadodra 390002, India

4 Hurvitz Brain Sciences Research Program, Sunnybrook Research Institute, Sunnybrook Health Sciences Centre, University of Toronto, Toronto M4N 3M5, Canada

5 Division of Neurology, Sunnybrook Health Sciences Centre, University of Toronto, Toronto M4N 3M5, Canada 